assay. Networking in Brucellosis Research. In Report of the United Nations University Brucellosis Research Network. Ed J. F. Frank. Tokyo, United Nations University Press. pp 1-11

CORBEL, M. J. \& MACMILLAN, A. P. (1996) OIE Manual of Standards for Diagnostic Tests and Vaccines. Chapter 3.2.1. Paris, OIE. pp 242-255

GREISER-WILKE, I., MOENNIG, V., THON, D. \& RAUTER, K. (1985) Characterization of monoclonal antibodies against Brucella melitensis. Zentralblatt für Veterinärmedizin B 32, 616-627

MACMILLAN, A. P., GREISER-WILKE, I., MOENNIG, V. \& MATHIAS, L. A (1990) A competition enzyme immunoassay for brucellosis diagnosis Deutsche Tierärztliche Wochenschrift 97, 83-85

NAKANE, P. K. \& KAWAOI, A. (1974) Peroxidase-labeled antibody. A new method of conjugation. Journal of Histochemistry and Cytochemistry 22, 10841091

\section{Reaction of farmed mink (Mustela vison) to argon-induced hypoxia}

\author{
M. RAJ, G. MASON
}

THREE procedures are widely used for killing farmed mink: an overdose of an injectable anaesthetic; exposure to carbon monoxide; or exposure to carbon dioxide. Mink are usually caught by hand and restrained in order to administer an intraperitoneal lethal injection and this restraint can be distressing to them (G. Mason, personal observation). Carbon monoxide should ideally be supplied from a pure source at a concentration of about 1 per cent by volume, but it is sometimes supplied as scarcely modified car exhaust gases. Carbon dioxide is advised to be supplied at a concentration of 100 per cent by volume, but it is sometimes presented at lower concentrations in air. When using gases, mink are caught and introduced into an apparatus containing the recommended levels of either carbon dioxide or carbon monoxide (Joergensen 1985).

The results of a previous study indicated that mink find carbon dioxide extremely aversive, and they rapidly withdrew their heads from the gaseous atmosphere (Cooper and others 1998). Therefore, it was concluded that carbon dioxide is not an ideal gas for killing mink on animal welfare grounds. However, it is not known whether mink find the induction of unconsciousness with carbon monoxide aversive, as carbon monoxide induces unconsciousness and death through deprivation of oxygen. Deprivation of oxygen per se administered by argon-induced hypoxia ( 2 per cent residual oxygen) was not found to be aversive in pigs (Raj and Gregory 1995, 1996), but mink, being semi-aquatic diving animals, could respond differently.

It has been suggested, for example, that the oxygen storage capacity of mink, which limits dive durations, is similar to that of the non-aquatic ferret Mustela furo (Dunstone and O'Connor 1979). However, the occurrence of progressive bradycardia and selective vasoconstriction induced by hypoxia (occurring as a consequence of diving apnoea) during submergence under water meets the energy requirements of vital organs in diving mink (Stephenson and others 1988). Indeed, it is now well known that bradycardia and associated changes in the vascular system are an adaptive response to diving apnoea in all vertebrates, including human beings. Since the occurrence of bradycardia per se is not distressing, mink will continue to forage under water until the bradycardia exceeds a threshold, at which point they will then emerge from the water to recover in atmospheric air before repeating a dive.
This study was carried out to determine the reaction of mink to the presence of argon-induced hypoxia ( 2 per cent residual oxygen).

A chamber was filled with 90 per cent argon with 2 per cent residual oxygen in air. The chamber also contained a novel object to test whether the presence of the gas would inhibit the motivation of the mink to investigate and interact with the novel object.

Three male and three female wild type mink (Mustela vison) were used. They were trained to expect a novel object on a floor-level bath tub as described by Cooper and others (1998). Training was conducted once a day for four days until they showed a stable level of interaction with the novel object.

On the fifth day, the mink were subjected to an air control in which they were allowed to enter the experimental chamber and interact with novel object as in the training period, and behavioural data were collected. The mink were then encouraged to move back into their home cage and the entrance to the chamber was locked. After two hours, the chamber containing a different novel object was filled with argon ( 2 per cent residual oxygen) and the mink were subjected to the argon treatment. Data collection ceased 10 minutes after the mink first entered the novel object chamber. During the treatment, the residual oxygen in the chamber was continuously monitored at the entrance to the chamber using a magnetic sensor (Servomex; Crowborough). In addition, the spontaneous behaviour of mink when returned to atmospheric air after exposure to argon was noted. As all the mink survived the argon treatment, a second air control trial was conducted on the next morning.

The following data were collected in each trial: the time taken to reach the novel object chamber from the home cage; the time taken to descend the ladder into the novel object chamber; the initial reaction, such as recoil, to exposure to the gas at the bottom of the ladder; the number of coughs and sneezes during exposure to the gas; the duration of each stay within the gas interacting with the novel object; and the number of visits to the novel object chamber

Initial statistical evaluation of the data showed that there were no significant differences between the two air controls, and, therefore, the data were pooled to derive a single set of means for the air control. These data were then compared with the argon data using the Wilcoxon Matched Pair Tests, with each mink as its own control, to determine the effects of the presence of argon in the chamber.

The results (Table 1) did not indicate that the mink could detect the presence of argon or that they had any aversion to the initial exposure to argon, as the mean times taken to descend the ladder in air and argon were not significantly different. This conclusion is also supported by the fact that the mink did not recoil from the chamber and they showed no sneezing or coughing during exposure to the gas. However, the duration of stay in the argon atmosphere was much reduced, indicating that the mink were able to detect and respond to the effects of hypoxia. This resulted in a significantly shorter total time spent in the chamber interacting with the novel object. After recovering in atmospheric air from the effects of hypoxia, the mink entered the argon atmosphere repeatedly, as shown by the increase in the total number of visits to the chamber. After leaving the argon atmosphere, the mink lay down and appeared to hyperventilate, showing twitching of abdominal muscles.

Argon is an inert gas with no odour or taste, and it is not surprising that the mink did not find the presence of the gas aversive. However, since prolonged exposure to argon results in reduced blood oxygen levels, it is likely that the mink responded to the resultant state of hypoxia as they left the chamber within 23 seconds. This is consistent with previous studies of diving in mink, showing that they do not spend long periods under water. In this respect, a range of five to 20
Veterinary Record (1999) 145, 736-737

M. Raj, BVSc, MVSc, PhD, Department of Clinical Veterinary Science, University of Bristol, Langford, Bristol BS40 5DU G. Mason, $\mathrm{BA}, \mathrm{PhD}$, Animal Behaviour Research Group, Department of Zoology, University of Oxford South Parks Road, Oxford OX1 3PS 


\begin{tabular}{|c|c|c|c|}
\hline Variable & $\begin{array}{c}\text { Median values (int } \\
\text { Air }\end{array}$ & $\begin{array}{l}\text { tile ranges) for } \\
\text { Argon }\end{array}$ & Probability \\
\hline $\begin{array}{l}\text { Time (seconds) taken to descend the } \\
\text { ladder into the novel object chamber } \\
\text { Number of recoils } \\
\text { Number of coughs and sneezes } \\
\text { during exposure } \\
\text { Time (seconds) to reach the novel } \\
\text { object chamber from the home cage } \\
\text { Duration (seconds) of each stay } \\
\text { within the gas, interacting } \\
\text { with the novel object } \\
\text { Mean number of visits to } \\
\text { novel object chamber } \\
\text { Longest duration (seconds) } \\
\text { of stay in the chamber } \\
\text { Total time (seconds) spent } \\
\text { in the chamber }\end{array}$ & $\begin{array}{c}1.3(1-1.5) \\
0 \\
0(0-1) \\
7.5(5-26-5) \\
200.8(159-5-306-5) \\
1.3(1-2) \\
290.3(180-306-5) \\
374.8(180-457)\end{array}$ & $\begin{array}{c}1.0(1-1) \\
0 \\
0(0-1) \\
23.0(5-180) \\
15.4(13-8-18) \\
6.5(1-7) \\
23.0(18-35) \\
99.0(18-129)\end{array}$ & $\begin{array}{c}P<0.05(Z=2.20) \\
\text { NS } \\
P<0.05(Z=2.20) \\
P<0.05(Z=2.20)\end{array}$ \\
\hline
\end{tabular}

NS Not significant

\section{ACKNOWLEDGEMENTS}

This research was funded by the Farm Animal Care Trust, UK.

\section{References}

COOPER, J., MASON, G. \& RAJ, M. (1998) Determination of the aversion of farmed mink (Mustela vison) to carbon dioxide. Veterinary Record 143, 359-361 DUNSTONE, N. (1983) Underwater hunting behaviour of the mink (Mustela vison Schreber): an analysis of constraints on foraging. Acta Zoologica Fennica 174, 201-203

DUNSTONE, N. \& O'CONNOR, R. J. (1979) Optimal foraging in an amphibious mammal. I. The aqualung effect. Animal Behaviour 27, 1182-1194 HANSEN, N. E., CREUTZBERG, A. \& SIMONSEN, H. B. (1991) Euthanasia of mink (Mustela vison) by means of carbon dioxide $\left(\mathrm{CO}_{2}\right)$, carbon monoxide (CO) and nitrogen $\left(\mathrm{N}_{2}\right)$. British Veterinary Journal 147, 140-146

JOERGENSEN, T. (1985) Mink Production. Ed. T. Joergensen. Hilleröd, Scientifur. p 348

LAMBOOY, E., ROELOFS, J. A. \& VAN VOORST, N. (1985) Euthanasia of mink with carbon monoxide. Veterinary Record 116, 416

POOLE, T. B. \& DUNSTONE, N. (1976) Underwater predatory behaviour of the American mink (Mustela vison). Journal of Zoology (London) 178, 395-412

RAJ, A. B. M. \& GREGORY, N. G. (1995) Welfare implications of gas stunning pigs 1. Determination of aversion to the initial inhalation of carbon dioxide or argon. Animal Welfare 4, 273-280

seconds has been reported to be typical of dive duration (Poole and Dunstone 1976, Dunstone 1983). It is possible that the mink used in the present study also experienced bradycardia as exposure to argon-induced hypoxia progressed and they left the chamber when it reached their threshold.

Hansen and others (1991) have reported that mink became unconscious (based on time to recumbency) in 76 seconds after exposure to anoxia created by using 100 per cent nitrogen. However, these researchers did not report whether the mink showed any aversive reactions during the induction of unconsciousness. The results of this study show that the mink responded to hypoxia, unlike pigs for example, by leaving the reward chamber rather than by continuing to interact with the novel object. Killing with carbon monoxide delivered from a source of 100 per cent carbon monoxide, rather than exhaust gases, has been suggested as a humane method (Lambooy and others 1985), however, during exposure to 100 per cent carbon monoxide, the average time to loss of consciousness was reported to be 64 seconds (Hansen and others 1991). This is rather prolonged, but it is not known whether mink find the presence of carbon monoxide aversive.

Based on the results of this study, it is suggested that prolonged, unforced exposure of mink to argon would result in bradycardia, and the extent of bradycardia is likely to be similar to that occurring during diving for foraging. However, mink also develop severe bradycardia very rapidly under frightening/stressful situations, and it is very likely that the catching and handling of mink before immersion into gases, as occurs on commercial farms, would also result in the rapid onset of a severe bradycardia (Stephenson and others 1988) From the mink's welfare point of view, it is important to establish the severity of bradycardia induced by the inevitable handling procedures and its interaction with the mink's physiological responses to hypoxia induced with argon or carbon monoxide. For example, if a threshold bradycardia (which presumably caused these mink to leave the hypoxic atmosphere) is induced by the handling procedures and subsequent exposure to hypoxia has no additive effect, then it could potentially render a hypoxic atmosphere less detectable. Alternately, if the exposure to hypoxia had an additive effect on the mink then the situation could be worse, that is, it could accelerate the time taken for the mink to respond to the hypoxic state. Beside these speculations, the fact that mink are capable of detecting and avoiding hypoxic states, forcing them to stay in a gaseous atmosphere until they are rendered unconscious, raises an important welfare issue that needs further investigation.
RAJ, A. B. M. \& GREGORY, N. G. (1996) Welfare implications of gas stunning pigs 2. Stress of induction of anaesthesia. Animal Welfare 5, 71-78

STEPHENSON, R., BUTLER, P. J., DUNSTONE, N. \& WOAKES, A. J. (1988) Heart rate and gas exchange in freely diving American mink (Mustela vison). Journal of Experimental Biology 134, 435-442

\section{ABSTRACTS}

\section{Bovine TB in brushtail possums}

THE levels of tuberculosis (ТВ) in brushtail possums were compared with the levels of the disease in cattle grazing in the same area of the Ahaura Valley, Westland, New Zealand, first in 1979 to 1980 and again from 1992 to 1996 . TB was first identified in the possums trapped in 1980, and the disease was present in each year from 1992 to 1996 . There appeared to be clusters of the infection in time and space, and the prevalence of the disease decreased as the population of possums, and their wellbeing, increased, and as their average age decreased. The prevalence of ТВ in possums was higher in 1980 and 1992 than in the later years and these peaks appeared to coincide roughly with upsurges in TB in nearby herds of cattle.

COLEMAN, J. D., COOKE, M. M., JACKSON, R. \& WEBSTER, R. (1999) New Zealand Veterinary Journal 47, 119

\section{Alternative route for the lead of a heart pacemaker in large dogs}

IN large dogs with a heart pacemaker there is a risk that excessive neck movements may dislodge the lead introduced through a jugular vein. This paper describes an alternative technique for introducing the lead of the pacemaker through the right costocervical vein. The technique was applied to six dogs, in five of which the lead in a jugular vein had become dislodged. In none of them did the new lead become dislodged during follow-up periods of 15 to 20 months.

FLANDERS, J. A., MOISE, N. S., GELZER, A. R. M., WASKIEWICZ, J. C. \& MACGREGOR, J. M. (1999) Journal of the American Veterinary Medical Association 215, 46 